\title{
Plasma Digoxin Concentrations in Patients with Atrial Fibrillation
}

\author{
D. A. CHAMBERLAIN, ${ }^{*}$ M.R.C.P. ; R. J. WHITE, $\dagger$ M.R.C.P. ; M. R. HOWARD $\ddagger$; T. W. SMITH,§ M.D.
}

\begin{abstract}
Ummary: Plasma digoxin concentrations were measured by radioimmunoassay in 116 patients with atrial fibrillation on long-term oral treatment with the drug, and in 23 patients with digoxin toxicity. The mean concentrations were $1.4 \mathrm{ng} . / \mathrm{ml}$. and $3.1 \mathrm{ng} . / \mathrm{ml}$., respectively. Though an overlap occurred between the therapeutic and toxic ranges, toxicity is unlikely to occur below a level of $2 \mathrm{ng}$./ $\mathrm{ml}$. Plasma concentration showed a poor correlation with resting heart rate during atrial fibrillation. In patients with good renal function, however, a significant correlation was found between oral dose and plasma concentration. No evidence was obtained for increased sensitivity to therapeutic concentrations of the drug in elderly subjects, but the doses required to achieve these concentrations tended to be less than in younger patients.
\end{abstract}

\section{Introduction}

The cardiac glycosides are among the oldest effective remedies in clinical medicine, but despite 200 years' experience problems still arise in determining optimal dose requirements. These problems have been only partly overcome by the availability of purified preparations such as digoxin. Considerable variation in tolerance occurs from patient to patient, yet the margin between effective digitalization and toxicity is small. There is often uncertainty whether unusual requirements are due to problems of absorption and excretion or whether they are due to variation in sensitivity. Until recently such problems could not readily be resolved, because methods for measuring therapeutic concentrations of the drug in blood and tissue were not available for routine clinical use. With the introduction of a sensitive radioimmunoassay technique (Smith, Butler, and Haber, 1969) plasma digoxin concentrations can be measured accurately and quickly. To determine the therapeutic range of plasma levels we have measured samples from many subjects on long-term oral therapy; we chose particularly patients with atrial fibrillation because we thought that ventricular rate during this arrhythmia provided the only convenient yardstick for measuring the effect of the drug. We have also measured plasma concentrations in patients with digoxin toxicity to define further the relation between the therapeutic and toxic ranges.

\section{Patients and Methods}

Plasma digoxin concentrations were measured in 116 patients with atrial fibrillation treated with long-term oral digoxin. Their ages ranged from 32 to 84 (mean 58) years. Eighty had rheumatic heart disease, 18 had ischaemic or hypertensive heart disease, nine had lone atrial fibrillation or heart disease of unknown aetiology, three had cor pulmonale, two had congenital heart disease, and the remaining four had respectively syphilitic aortic regurgitation, haemochromatosis, constrictive pericarditis, and controlled thyrotoxicosis. All were receiving inpatient or outpatient care at St. Bartholomew's Hospital.

\footnotetext{
*Senior Medical Registrar, St. Bartholomew's Hospital, London E.C.1. Present address: Royal Sussex County Hospital, Brighton, Sussex. † Medical Registrar, St. Bartholomew's Hosnital. London E.C.1.

$\ddagger$ Research Technician, St. Bartholomew's Hospital, London E.C.1.

§Staff Physician, Cardiac Unit, Massachusetts General Hosfital, Bəst'n, Mass. 02114.

Reprint requests to Dr. D. A. Chamberlain.
}

For comparative purposes digoxin levels were also measured in two other groups of subjects. The first group consisted of 50 individuals who were not receiving digoxin and therefore acted as controls; 24 of these were patients with a variety of diseases, including malignancy, and 26 were healthy volunteers. The second group consisted of 22 patients at St. Bartholomew's Hospital and the National Heart Hospital who were considered to have digoxin toxicity. All had electrocardiograms (E.C.G.s) which were compatible with this diagnosis, and most had shown more than one electrocardiographic abnormality suggestive of toxicity. The principal rhythm abnormalities were as follows: accelerated junctional rhythm with or without heart block in 10 patients, very frequent ventricular ectopic beats or coupling in seven, atrial tachycardia with block in three and partial heart block in two. Seven of these patients died in hospital; in nine others we were able to obtain follow-up E.C.G.s which showed disappearance of the characteristic rhythm abnormality as the plasma digoxin levels fell.

Plasma digoxin levels were measured by radioimmunoassay, the technique differing only slightly from that previously described (Smith et al., 1969, 1970). Heparinized blood samples were drawn about 8 to 24 hours after the last oral dose, and plasma was obtained by centrifugation. If determinations were not carried out immediately the samples were stored at $-10^{\circ} \mathrm{C}$. To two duplicate $1-\mathrm{ml}$. aliquots of plasma containing an unknown amount of unlabelled digoxin was added $2 \cdot 2 \mathrm{ng}$. of tritiated digoxin* $\left(1 \mathrm{ng}\right.$. $=10^{-9} \mathrm{~g}$.). Antibody, previously designated antibody 700/32 (Smith et al., 1970), was then added in sufficient quantity to bind only $55 \%$ of the tritiated digoxin in the absence of any unlabelled drug, and the mixture was incubated at room temperature for at least 15 minutes. Competition occurred for the available binding sites between the known labelled digoxin and the unknown unlabelled digoxin; the greater the quantity of the drug originally present, the smaller the amount of labelled digoxin in the antigen-antibody complex.

The complex was separated from the digoxin remaining unbound by adsorbing the latter on to dextran-coated charcoal (Herbert, Lau, Gottlieb, and Bleicher, 1965), which was then precipitated by centrifugation. The supernatant was added to $10 \mathrm{ml}$. of liquid scintillation medium, Bray's (1960) solution or NE $250 \dagger$ and heated in an oven at $80^{\circ} \mathrm{C}$. for 60 minutes to complete denaturation of the antibody and so release digoxin from the binding sites. Precipitated protein residue was packed as firmly as possible by centrifugation to the bottom of the counting phials and the supernatant counted in a Beckman .LS.100 liquid scintillation -counter. Correction for quenching due to constituents of the plasma was made by the use of internal standards. Percentage binding of tritiated digoxin was then calculated. A standard curve relating bound tritiated digoxin to levels of the drug in $\mathrm{ng} . / \mathrm{ml}$. was obtained by performing the assay procedure on a series of solutions prepared by adding known amounts of crystalline digoxin to normal human plasma. The curves obtained for each batch of determinations were all closc!y similar.

Average resting heart rate in the patients with atrial fibrillation was measured with a Sanborn direct-writing electrocardiograph at a paper speed of $25 \mathrm{~mm}$. per second by

*Specific activity 3.2 Ci per mM. NEN Chemicals CMGH 6072 Dreieichenhain bei Frankfurt/Main, Postfach 71, Siemenstrasse 1, Germany.

†Nuclear Enterprises Ltd., Sighthill, Edinburgh 11. 
counting the QRS complexes in a long strip recorded over 30 seconds.

Potassium and urea levels were measured in the routine laboratory by Technicon AutoAnalyzer.

\section{Results}

The value for plasma digoxin levels was taken to be the mean of the two readings obtained from the duplicate aliquots from each sample. The average difference between duplicates was $0.2 \mathrm{ng} . / \mathrm{ml}$.

In 116 patients with atrial fibrillation we found digoxin levels ranging from less than $0.25 \mathrm{ng} . / \mathrm{ml}$. (below the limit of the sensitivity of the assay) to $3.2 \mathrm{ng} . / \mathrm{ml}$. The mean value was $1.4 \mathrm{ng} . / \mathrm{ml}$. ( \pm S.D. 0.7).

Twenty-one of the 22 patients with digoxin toxicity had levels ranging from 2.0 to $5.2 \mathrm{ng} . / \mathrm{ml}$. The other patient who had excellent clinical and electrocardiographic evidence of toxicity had a value of only $0.7 \mathrm{ng} . / \mathrm{ml}$; however, both digitalis folia and digoxin had been prescribed before admission to hospital, and glycosides other than digoxin still present in the plasma would not have been measured by the assay. The overall mean value for the toxic group was $3 \cdot 1 \pm 1 \cdot 1 \mathrm{ng} . / \mathrm{ml}$. significantly greater than the mean value for the patients without evidence of toxicity $(P<0.001)$.

Forty-nine of the control 50 individuals did not give readings suggesting that digoxin was present in the plasma; a single sample from a healthy subject gave a reading of 0.3 ng./ml., but repeated measurements from the same subject on subsequent occasions were all negative.

The data from the group with atrial fibrillation were further examined in relation to ventricular rate, daily dose, and the age of the patients.

\section{Plasma Levels and Ventricular Rate}

A poor correlation was found between ventricular rate and plasma levels of digoxin in patients with atrial fibrillation. Data from 100 of the 116 patients were suitable for analysis in that E.C.G.s were available for heart rate measurements, serum potassium levels were normal, and other drugs which could influence heart rate were not administered. An arbitrary division was made between those with resting heart rates ranging from 60 to 85 beats/minute and those with rates exceeding 85 beats/minute. The data are presented in full in Fig. 1 together with observations from the control group and the toxic group for purposes of comparison. The patients with relatively slow heart rates had a mean plasma digoxin level of $1.6 \pm 0.7 \mathrm{ng} . / \mathrm{ml}$. compared with a mean of $1.2 \pm 0.7$ ng. $/ \mathrm{ml}$. for the patients with faster rates, but the range was similar. The records of the 100 patients were examined, and in 44 cases E.C.G. evidence was found of rapid heart rates (120 beats/minute or faster) either at rest or during exercise during the 12-month period before digoxin levels were measured. The tendency within this group was for those with slower rates to have higher plasma digoxin levels (Fig. 2). The relationship just failed to be significant at the 5\% level of probability.

\section{Plasma Levels and Dose}

Sixty-eight of the 116 patients were considered suitable for this analysis on the basis of normal or near-normal renal function judged by blood urea levels of less than $40 \mathrm{mg} . / 100$ $\mathrm{ml}$. (Blood urea determination gives a value about twice that of blood urea nitrogen generally used in U.S.A.) The relationship of daily dose to plasma levels was clearly demonstrated $(r=0.783, P<0.001)$. Patients receiving $0.125 \mathrm{mg}$ daily had a mean level of $0.5 \pm 0.2 \mathrm{ng} . / \mathrm{ml}$; with 0.25 to 0.375 mg. daily the level was $0.9 \pm 0.4 \mathrm{ng} . / \mathrm{ml}$; with $0.5 \mathrm{mg}$. it was $1.5 \pm 0.4 \mathrm{ng} . / \mathrm{ml}$.; and with 0.625 to $0.75 \mathrm{mg}$. it was $2.1 \pm 0.6$ ng./ml. (Fig. 3).

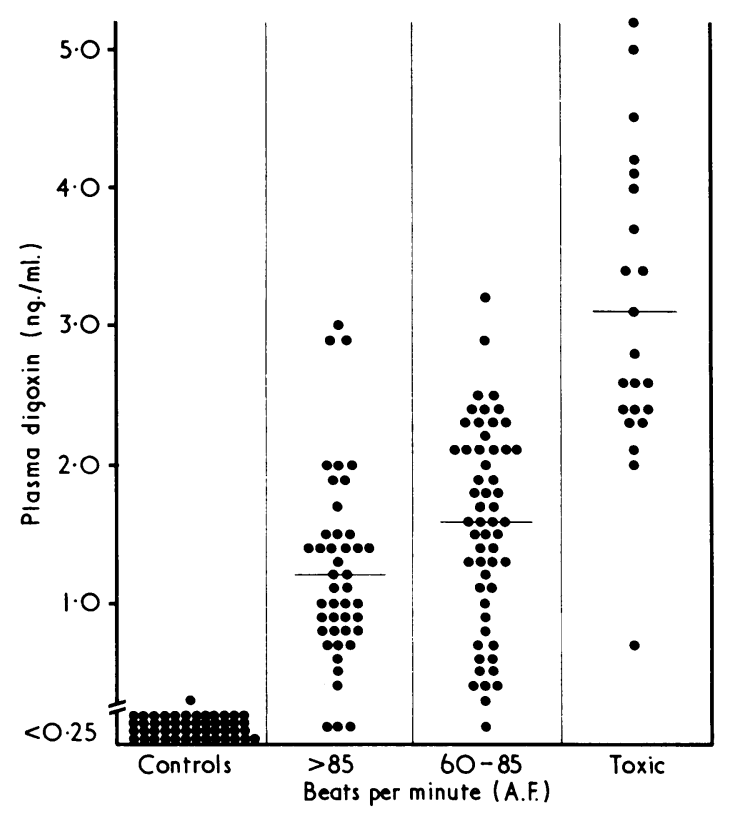

Fig. 1.-Plasma digoxin concentrations in 44 patients with atrial fibrillation and relatively fast heart rates and in 56 patients with atrial fibrillicition and relatively fast heart rates and in 56 patients with atrial Conilation and 22 patients with digonic Concentrations in 22 patients with digoxin toxicity and in 50 contro values.

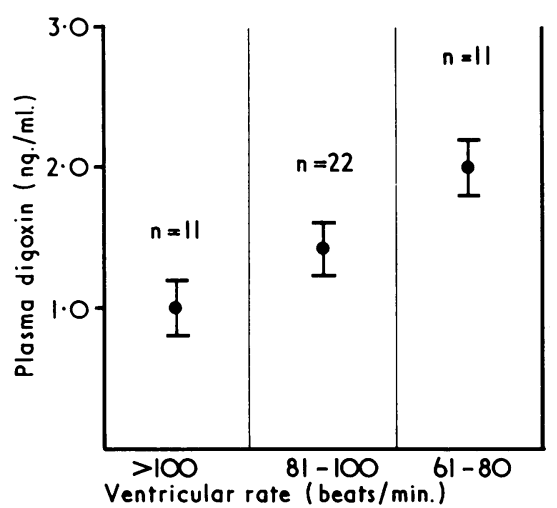

Fig. 2.-Plasma digoxin concentrations (mean with standard errors) plotted against heart rate in 44 patients with atrial fibrillation. All of the group were normokalaemic and had electrocardiographic evidence of rapid heart rates within 12 months of the plasma measurements.

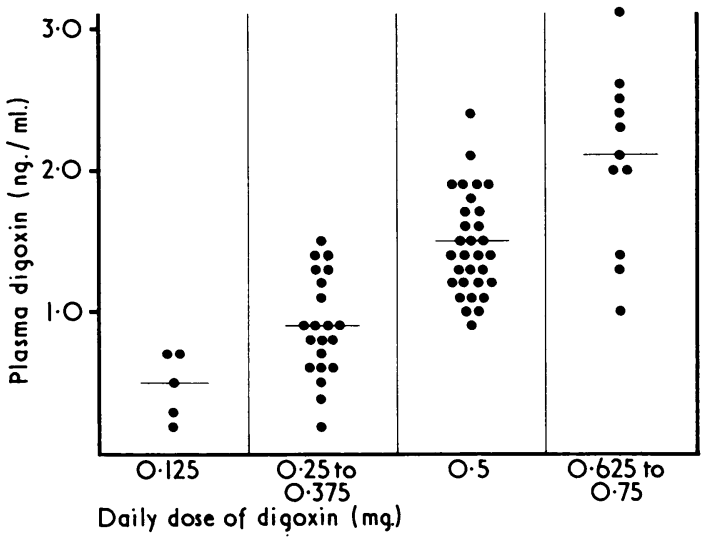

Frg. 3.-Plasma digoxin concentrations plotted against oral dose of digoxin in 68 patients. All had normal or near-normal renal function. The horizontal bars represent mean values. 


\section{Plasma Levels and Age}

The possibility of increased sensitivity to digoxin in the elderly was examined by comparing concentrations in patients under 60 years of age with those aged 60 and over. Only patients with well-controlled ventricular rates were considered (60 to 80 beats/minute). Data from 51 patients met this criterion. The mean concentrations in both groups were identical at $1.5 \mathrm{ng} . / \mathrm{ml}$., but the scatter was slightly greater in the elderly (Fig. 4).

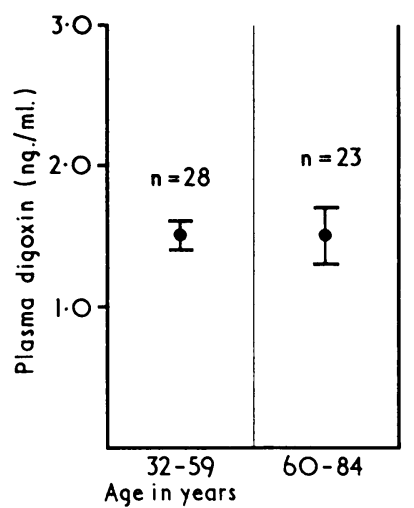

Fig. 4.-A comparison of plasma digoxin concentrations (mean with standard errors) in 28 patients under the age of 60 and 23 aged 60 to 84. All had well-controlled atrial fibrillation with resting heart rates in the range 60 to 80 beats/minute.

The levels in the older age group were attained with a mean dose of digoxin of $0.32 \mathrm{mg}$. per day compared with 0.42 $\mathrm{mg}$. per day in the younger group $(\mathrm{P}<0.05)$. More of the elderly patients had impaired renal function, judged by blood urea concentrations greater than $40 \mathrm{mg} . / 100 \mathrm{ml}$., and this was thought to account for the smaller dose requirement. The data for the older group were examined by multiple regression analysis, which confirmed that plasma concentrations of digoxin were related both to the dose of the drug and to the blood urea concentrations $(r=0.592, \mathrm{P}<0.01)$.

\section{Discussion}

The degree of digitalization of patients would best be reflected by myocardial concentrations. This measurement is clearly not feasible for routine clinical use, but plasma concentrations have been shown to bear enough relationship to those in the myocardium (Doherty, Perkins, and Flanigan, 1967) to be of clinical value. Patients receiving therapeutic doses of digoxin have very low concentrations in the blood, and for this reason assay procedures have been difficult to develop. The sensitive radioimmunoassay technique recently applied to the measurement of serum or plasma digoxin levels followed the demonstration by Butler and Chen (1967) that digoxin-specific antibodies can be raised in rabbits immunized with digoxin-protein conjugates. The high affinity and specificity of the antibodies prepared in this way have been reported by Smith et al. (1970), and the same authors described in detail the principles and method of the assay (Smith et al., 1969). In addition to its specificity the assay has other considerable advantages. It is technically simple to perform and, apart from the liquid scintillation counter, no expensive equipment is required. Because no extraction of digoxin is involved, it is relatively quick, and if necessary can provide an answer with little loss of precision within an hour.

The therapeutic range of values determined by radioimmunoassay accords closely with that found after the administration of tritiated digoxin to patients with subsequent measurement of radioactivity in serum (Marcus, Burkhalter, Cuccia, Pavlovich, and Kapadia, 1966). Concentrations of digoxin determined by ${ }^{86} \mathrm{Rb}$-transport inhibition, however, seem to be nearly twice as high as those determined by the present technique (Grahame-Smith and Everest, 1969). Under normal circumstances not more than $15 \%$ of digoxin is metabolized (Marcus, Kapadia, and Kapadia, 1964), but some cumulation of metabolites capable of inhibiting red cell ${ }^{86} \mathrm{Rb}$ transport may occur and account for this difference. On the other hand, some of the disparity in reported results may relate to variations in the time at which samples were taken in relation to the patients' previous doses of digoxin. We have found a sharp rise in plasma level within 15 to 30 minutes of $0.5 \mathrm{mg}$. orally, and the concentration takes four to six hours to settle again to a plateau as an equilibrium is reestablished between blood and tissues. We believe that blood samples drawn sooner than six to eight hours after tablets have been taken may not accurately reflect tissue levels.

\section{Plasma Levels}

Where it is possible to make a direct comparison between values obtained in the present study carried out in London and values based on the same technique previously reported from Boston (Smith et al., 1969) the agreement is excellent. Thus patients with normal renal function receiving $0.5 \mathrm{mg}$. of digoxin daily gave mean levels of $1.5 \pm 0.4 \mathrm{ng} . / \mathrm{ml}$. in London compared with $1.4 \pm 0.4 \mathrm{ng} . / \mathrm{ml}$. in Boston. With the exception of a single anomalous result which was probably due to the presence in the sample of glycosides other than digoxin, we found toxicity to be associated with levels of $2.0 \mathrm{ng} . / \mathrm{ml}$. and above (mean $3 \cdot 1 \pm 1 \cdot 1$ ), compared with the previously reported figure of $2.1 \mathrm{ng} . / \mathrm{ml}$. (mean $3.3 \pm 1.5$ ).

The plasma levels of digoxin in a large group of patients with atrial fibrillation on long-term treatment with the drug are now reported for the first time. The levels ranged from less than 0.25 to $3.2 \mathrm{ng} . / \mathrm{ml}$. Though the mean value was only $1.4 \mathrm{ng} . / \mathrm{ml}$., no fewer than 21 of the 116 patients had plasma concentrations of more than $2 \mathrm{ng} . / \mathrm{ml}$. and were therefore in the range which has been associated with digoxin toxicity. Of these 21 patients all but three were receiving $0.75 \mathrm{mg}$. of digoxin daily, or had evidence of impaired renal function. An important reason for the high plasma digoxin concentration in some patients with atrial fibrillation lies in the readiness of clinicians to regard the rate of ventricular response as a suitable yardstick for adjusting dose requirements. While this is appropriate in most instances, we found that it was not uncommon for plasma levels above $2 \mathrm{ng} . / \mathrm{ml}$. to be necessary to achieve control; in three patients resting heart rate exceeded 85 beats/minute despite plasma levels of 2.9 to $3.0 \mathrm{ng} . / \mathrm{ml}$.

The overlap which has been shown to exist between the therapeutic and toxic ranges strikingly demonstrates the dangerously low therapeutic ratio of digoxin, and explains the high incidence of adverse reactions to the drug, noted to be nearly $20 \%$ in one recent survey of hospital inpatients (Hurwitz and Wade, 1969).

\section{Evidence of Toxicity}

The factors which determine whether or not a patient will show evidence of toxicity are complex and ill-understood. The concentrations of potassium (Sampson, Alberton, and Kondo, 1943) and magnesium (Seller et al., 1970) are known to be important, and sodium balance (Harrison and Wakim, 1969) and thyroid state (Doherty, 1968) have also been shown experimentally to affect myocardial concentration of digoxin. Atrial fibrillation itself may mask toxicity because increasing delay in $\mathrm{A}-\mathrm{V}$ conduction cannot be revealed by a lengthening $\mathrm{P}-\mathrm{R}$ interval, and the irregular rhythm tends to prevent persistent coupling of ventricular ectopic beats (Friedberg, 1969). Electrocardiographic evidence of toxicity may become all too apparent if atrial fibrillation is converted to sinus rhythm by 
electrical cardioversion without a suitable period of withdrawal of digoxin (Gilbert and Cuddy, 1965). It seems likely that many patients with atrial fibrillation have latent digoxin toxicity which can readily become manifest without any increase in plasma concentration of the drug.

In view of the wide variations in dose requirements needed to achieve control of the heart rate in atrial fibrillation, and the fact that many patients with atrial fibrillation may have slow heart rates with or without digoxin, the poor correlation between ventricular rate and plasma levels was to be expected. The extent to which plasma levels reflect myocardial concentrations in chronically digitalized patients, however, remains to be defined.

\section{Daily Dose and Plasma Levels}

The relationship between the size of the daily dose and the plasma levels of digoxin was investigated. Because most of the drug is excreted unchanged by the kidneys (Marcus et al., 1964), renal function is as important as dose in determining blood levels. We therefore restricted the analysis to those patients who had normal or near-normal renal function indicated by blood urea concentrations of less than 40 mg. $/ 100 \mathrm{ml}$. The data presented in Fig. 3 show a significant relationship between oral dose and plasma levels. Several factors must have militated against more uniform blood levels. The patients were of different heights and weights; blood urea provides only a rough index of glomerular filtration rate; the potency of some commercially available digoxin tablets may vary widely (Feinberg, 1969); and blood samples were taken at intervals after the previous dose ranging from about 8 to 24 hours. Clearly, however, $0.5 \mathrm{mg}$. of digoxin daily will usually provide plasma levels in a satisfactory therapeutic range of 1 to $2 \mathrm{ng} . / \mathrm{ml}$. in the presence of normal renal function. Larger doses, or moderate doses in the presence of considerably impaired renal function, are associated with levels which fall within the toxic range.

Digoxin toxicity is particularly common in the elderlv (Soffer, 1961), and the suggestion has been made that this may be due in part to increased sensitivity to the drug (Feibush, 1959). We found, however, that blood levels in patients aged 60 and over with controlled atrial fibrillation were closely similar to the levels in younger patients (Fig. 4). The blood levels in the older age group were attained with a smaller mean dose, and the blood urea of these patients tended to be higher than those found in the under- 60 group. This observation is consistent with the findings of Ewy,
Kapadia, Yao, Lullin, and Marcus (1969), who used tritiated digoxin to show that a given dose of the drug resulted in higher blood concentrations in the elderly compared with younger subjects, and that the difference was associated with smaller body size and diminished urinary excretion of digoxin.

The present findings indicate that the ventricular response to atrial fibrillation is not well correlated with plasma concentration of digoxin. Patients receiving more than $0.5 \mathrm{mg}$. daily or those having smaller doses in the presence of impaired renal function may have blood concentrations in the range often associated with toxicity, irrespective of heart rate. Though high blood levels are often well tolerated, the risk of digoxin toxicity must be carefully weighed against the need for large doses of the drug.

We are grateful to the physicians at St. Bartholomew's Hospital and the National Heart Hospital for allowing us to study patients under their care. We are also indebted to Dr. Edgar Haber, Dr. G. W. Hayward, Dr. J. Hamer, Professor J. Landon, Dr. T. Chard, and Dr. D. Gibson for help and advice. The crystalline digoxin was kindly supplied by Messrs. Burroughs Wellcome \& Co.

\section{REFERENCES}

Bray, G. A. (1960). Analytical Biochemistry, 1, 279. Butler, V. P., and Chen, J. P. (1967). Proceedings of the National
Academy of Sciences of the United States of America, 57, 71.

Doherty, J. E. (1968). American fournal of the Medical Sciences, 255, 382 .

Doherty, J. E., Perkins, W. H., and Flanigan, W. J. (1967). Annals of Internal Medicine, 66, 116.

Ewy, G. A., Kapadia, G. G., Yao, L., Lullin, M., and Marcus, F. I. (1969). Circulation, 39, 449

Feibush, J. S. (1959). American fournal of Cardiology, 3, 121.

Feinberg, M. (1969). Fournal of the American Pharmaceutical Association, 9.113.

Friedberg, H. D. (1969). American Heart fournal, 77, 429.

Gilbert, R., and Cuddy, R. P. (1965). Circulation, 32, 58.

Grahame-Smith, D. G., and Everest, M. S. (1969). British Medical Fournal, 1. 286 .

Harrison, C. E., and Wakim, K. G. (1969). Circulation Research, 24,

Herbert. V.. Lau, K.. Gottlieb, C. W., and Bleicher. S. I. (1965). fournal of Clinical Endocrinology and Metabolism, 25, 1375.

nul of Clinical Endocrinology and Metabolism, 25, 1375.

Hurwitz, N., and Ware. O. L. (1969). British Medical fournal, 1, 531 . G. G. (1966). Circulation, 34, 865.

Marcus. F. I.. Kanadia. G. I.. an ${ }^{2}$ Kapadia. G. G. (1964). Fournal of Pharmacology and Experimental Therapeutics, 145, 203.

Sampson, J. J., Alberton, E. C., and Kondo, B. (1943). American Heart Fournal, 26. 164 .

Seller. R. H., et al. (1970). American Heart fournal, 79. 57.

Smith, T. W., Butler, V. P., and Haber, E. (1969). New England fournal of Medicine, 281, 1212 .

Smith. T. W.. Butler, V. P., and Haber, E. (1970). Biochemistry (Washington), 9,331 .

Soffer, A. (1961). Archives of Internal Medicine, 107, 681.
Spencer (1968) reported the deaths of two patients while they were undergoing therapeutic starvation. Garnett et al. (1969) reported the death of a young woman on the seventh day of

\footnotetext{
* Lecturer in Materia Medica, University of Glasgow, at Stobhill General
} Hospital, Glasgow N.1.

† Consultant Physician, Stobhill General Hospital, Glasgow N.1. refeeding following a fast of 30 weeks. At necropsy fragmentation of the cardiac myofibrils was found. This led them to stigmatize therapeutic starvation as an unsafe procedure. These reports have stimulated us to review our experience in particular the possible hazard to the patient during therapeutic starvation. We also wish to describe some side-effects of fasting which, to our knowledge, have not previously been reported.

Probably the incidence of any hazard due to therapeutic starvation will rise with increasing length of fast of patients. In this context we have arbitrarily defined prolonged starvation as for a minimum period of 60 days. To date, in this series, 18 patients have undergone periods of fasting of at least 60 days. The details of these patients-length of fast and weight loss-are shown in the Table. 